\title{
A posição em que Cristo deve estar no âmbito transcendental do campo da fé: uma leitura teológica do "campo de realidade" zubiriano
}

\begin{abstract}
The position in which Christ must be in the transcendental ambit of the field of faith: a theological reading of the Zubirian "field of reality"
\end{abstract}

Valeriano dos Santos Costa

\section{Resumo}

Esse artigo tem como objeto formal a posição em que Cristo deve estar no âmbito transcendental do campo de realidade da fé. Esta posição na teologia aparece muito claro na afirmação da única coisa necessária que Cristo dá como norma a Marta de Betânia. Porém queremos realizar uma busca na filosofia zubiriana para saber se é possível ajustar esta norma de Cristo ao campo de realidade zubiriano. A nossa intuição é que seja possível, pois campo de realidade em Zubiri é uma questão de atualização, isto é, de apreensão da realidade da coisa real pela impressão de realidade que os sentidos oferecem. Então Teologia e Filosofia se encontram naquilo que Zubiri chama de inteligência senciente. A Vulgata eternizou a norma dada por Jesus a Marta de Betânia como unum necessarium. É por isso que a posição em que Cristo deve estar no âmbito transcendental da fé já é uma questão zubiriana.

Palavras-chave: Realidade. Fé. Campo. Transcendência. Âmbito. 


\begin{abstract}
This article has as its formal object the position in which Christ must be in the transcendental ambit of the reality field of faith. This position in theology appears very clear in the affirmation of the only necessary thing that Christ gives to Martha of Bethany as a norm. However, we want to carry out a search in Zubirian philosophy to find out if it is possible to adjust this standard of Christ to the field of Zubirian reality. Our intuition is that it is possible, because the field of reality in Zubiri is a matter of updating, that is, of apprehending the reality of the real thing by the impression of reality that the senses offer. So Theology and Philosophy meet in what Zubiri calls sentient intelligence. The Vulgate eternalized the rule given by Jesus to Marta of Bethany as unum necessarium. That is why the position in which Christ must be in the transcendental ambit of faith is already a Zubirian issue.
\end{abstract}

Keywords: Reality. Faith. Field. Transcendence. Ambit.

\title{
Introdução
}

O tema que nos propusemos pesquisar já mostra desde o título que vamos navegar na interdisciplinaridade, fazendo interface entre Teologia e Filosofia. Mas não se trata de uma filosofia convencional, mas de uma filosofia inovadora e revolucionária, que, sem atravessar o horizonte da fenomenologia, foi muito mais longe do que os mais conceituados fenomenólogos conseguiram chegar. Uma expressão desta verdade é que para Zubiri o dar-se conta da realidade não é o momento primário ou imediato, mas fundado de modo articulado no momento mesmo de atualidade, opondo-se ao meramente intencional da fenomenologia de Husserl como diz Solari. ${ }^{1}$ E aqui repousa a tese de que Zubiri, mesmo sendo considerado fenomenológico pela maioria dos autores, não é discípulo estritamente falando de nenhum deles, como diz Manero a respeito do seu discipulado de Ortega y Gasset: "Zubiri nunca se considerou discípulo de Ortega. Teve seu pensamento próprio. ${ }^{2}$ Mas isso pode ser controverso, pois há autores como Sancho, que pensam que "é possível que

\footnotetext{
${ }^{1}$ SOLARI, E., La raiz de lo sagrado, p. 123.

${ }^{2}$ MANERO, M. M., Era Independiente de Ortega, p. 43.
} 
Ortega tenha uma intervenção maior na tese de Zubiri do que se acreditou". ${ }^{3}$ O importante que é a obra madura de Zubiri, a inteligência senciente, é uma baliza para se conhecer realmente o pensamento deste filósofo, como afirma entre muitos Tirado San Juan. ${ }^{4}$ Então estamos falando da filosofia do espanhol Xavier Zubiri, que terminou sua busca apaixonada pela verdade em 1983, quando morreu, deixando o legado de sua pesquisa para ser levado à frente por outros amantes da verdade.

Assim, Zubiri foi em busca de um novo modo de conhecimento que a Teologia não deve ignorar. Teologia e Filosofia sempre tiveram estreita proximidade, embora o jargão ancilla Theologiae atribuído à Filosofia, não tenha sido proveitoso para nenhuma das duas. ${ }^{5}$ Contudo, concordam os autores que a Teologia não pode nem deve prescindir da metafísica. Mas de qual metafísica? Não, certamente, da metafísica clássica, pois aquela metafísica, segundo Tejada e Cherubin, está em crise desde a segunda metade do século XIX. ${ }^{6}$ Consciente disso, Heidegger pensa que “confundir o 'ontológico' com o meramente 'ôntico', é o grande mal da metafísica ao longo dos séculos". ${ }^{7}$

É aí que entra a novidade zubiriana. Sua metafísica que está no horizonte do século XXI. Mas como diz Zubiri, "o horizonte da metafísica é um horizonte de totalidade. Porém, além do mais, é um horizonte de ultimidade. A metafísica pretende ir ao último da totalidade das coisas". ${ }^{8} \mathrm{E}$ a Teologia, se quiser falar ao homem deste século, precisa fundamentar-se numa metafísica deste cunho, que para nós é, sem dúvida, a metafísica enquadrada na noologia zubiriana. É natural que seja difícil no âmbito de um artigo como este oferecer uma base minimamente consistente de um pensamento tão complexo e profundo como o de Zubiri. Só assim se estabelece o diálogo com a Teologia. No entanto, ousar é preciso. Então sabendo do risco, vamos tentar

\section{O ponto de partida: o texto bíblico}

Para introduzir o tema deste artigo, consideramos necessário apresentar antemão o texto bíblico que nos interessa diretamente, o qual não vai ser

\footnotetext{
${ }^{3}$ SANCHO, J. C., Zubiri e Heidegger desde Ortega y Gasset, p. 82.

${ }^{4}$ TIRADO SAN JUAN, V. M., Husserl et Zubiri, p. 40.

${ }^{5}$ PINTOR-RAMOS, A., Genesis y formación de la filosofia de Zubiri, p. 33.

${ }^{6}$ TEJA, J. F.; CJERUBIN, F., “O amor à sabedoria” em Xavier Zubiri, p. 43.

${ }^{7}$ GUILLÉN, D. G., El problema del fundamento, p. 43.

${ }^{8}$ ZUBIRI, X., Estructura dinâmica de la realidad, p. 104.
} 
alvo de uma exegese certamente, porque não é o âmbito de nossa pesquisa, mas como coluna dorsal deverá estar em foco durante todo o desenrolar do pensamento. $\mathrm{E}$ advertimos antecipadamente que os termos subiríanos que aparecem nesta introdução serão alvo de estudo no decorrer do trabalho.

Estando em viagem, entrou num povoado, e certa mulher, chamada Marta, recebeu-o em sua casa. Sua irmã, chamada Maria, ficou sentada aos pés do Senhor, escutando-lhe a palavra. Marta estava ocupada pelo muito serviço. Parando, por fim, disse: "Senhor, a ti não importa que minha irmã me deixe assim sozinha a fazer o serviço? Dize-lhe, pois, que me ajude". O Senhor, porém, respondeu: "Marta, Marta, tu te inquietas e te agitas por muitas coisas. No entanto, pouca coisa é necessária, até mesmo uma só. Maria, com efeito, escolheu a melhor parte, que não lhe será tirada" (Lc 10,38-42).

$\mathrm{O}$ sujeito não aparece no texto nem antes e nem depois com o interpelativo nominal Jesus. É o contrário em relação às duas mulheres e irmãs Marta e Maria, pois se insiste em nomeá-las. Jesus, no entanto, é referido com o atributivo cristológico "Senhor". Portanto, a perícope desenvolve-se no âmbito da fé pascal, e o ensino que aqui se transmite está em vista da centralidade do Cristo, ou de Jesus de Nazaré como o Cristo, cuja posição queremos analisar pela interdisciplinaridade com a filosofia de Xavier Zubiri. A Bíblia de Jerusalém, em nota de rodapé, afirma que há uma variante que, em vez de dizer: "no entanto, pouca coisa é necessária", afirma: "no entanto uma só coisa é necessária". Isso mutila o texto e altera o sentido, pois Jesus passa da perspectiva da refeição ("pouca coisa é necessária") a do único necessário. ${ }^{9}$ No nosso entender, é a perspectiva eucarística do Reino, que está muito presente em todo o Evangelho de Lucas. Da refeição de peregrinos se parte para a comensalidade do Reino de Deus. Pouca coisa é necessária para nos colocarmos em unidade comensal quando se tem a noção do único necessário em função do qual vivemos e somos.

Vamos partir do coração da perícope, que é o logos afirmativo de Jesus em resposta à questão apresentada por Marta: "Senhor, a ti não importa que minha irmã me deixe assim sozinha a fazer o serviço? Dize-lhe, pois, que me ajude. Disse Jesus: Marta, Marta, tu te preocupas e te agitas por muitas coisas" (Lc 10,41). Esta afirmação de Jesus pode ser enquadrada no âmbito do

\footnotetext{
${ }^{9}$ F, referente ao comentário do versículo de 10,42 do Evangelho de Lucas da Bíblia de Jerusalém.
} 
campo de realidade zubiriano, ou seja, é um logos que afirma que umas coisas estão em função de outras, ${ }^{10}$ pois que "a coisa seja campal tem justamente um caráter de funcionalidade meramente radical". ${ }^{11}$ Segundo Zubiri, uma forma de funcionalidade entre as coisas reais é a "coexistência". E nesta coexistência, "cada coisa real ocupa uma posição no campo por uma função campal no dito campo". ${ }^{12}$ Por isso, "todo real, 'por' ser campalmente real é funcionalmente 'por' alguma realidade". ${ }^{13}$

A indagação deste artigo por qual é a posição em que Cristo está no âmbito transcendental do campo da fé é feita no bojo da questão da funcionalidade zubiriana. Zubiri já indica que pode estar "em primeiro plano ou na periferia, etc." ${ }^{14}$ Então vamos à resposta do próprio Cristo a Marta: "pouca coisa é necessária, até mesmo uma só" (Lc 10,42). A resposta de Cristo já está dada: sua posição é o primeiro plano.

Agora vamos desenvolver nossa argumentação, estudando com algum rigor as terminologias zubirianas em seu sentido filosófico estrito para podermos aplicar com segurança à Teologia. Vejamos: realidade, campo de realidade, funcionalidade campal, âmbito transcendental, a atualização de umas coisas entre outras, o indefinido e sua diferença do não definido, o panorama campal.

\section{Conceitos subiríanos fundamentais para o nosso tema}

Vamos tratar de alguns conceitos subiríanos que não podem deixar de ser estudados, mesmo resumidamente para podermos fazer interface com a teologia no tema proposto. No entanto, em alguns momentos já começaremos a tecer considerações e aproximações teológicas.

\subsection{Realidade}

Temos aí algo de peso fundamental na filosofia de Zubiri: a realidade. Mas em Zubiri realidade é algo inteiramente novo. É especificamente humano, o que estabelece a diferença entre o homem e os demais seres vivos,

\footnotetext{
${ }^{10}$ ZUBIRI, X., Inteligência e logos, p. 22.

${ }^{11}$ ZUBIRI, X, Inteligência e logos, p. 23.

${ }^{12}$ ZUBIRI, X., Inteligência e logos, p. 23.

${ }^{13}$ ZUBIRI, X., Inteligência e logos, p. 25.

${ }^{14}$ ZUBIRI, X., Inteligência e logos, p. 3.
} 
que Zubiri chama tecnicamente de "animais". Sem aprofundar, temos de notar que os animais têm estimulidade apenas, e o homem, realidade. Este suspende ao menos sua atitude de apreender impressivamente a estimulação e, sem a negar, faz uma operação que nós adultos chamamos dar-se conta da realida$d e .^{15}$ Normalmente confundimos realidade com a coisa real, e isso nos leva a equívocos graves. A coisa real está fora ou está em nós quando falamos de realidade humana. Mas mesmo falando de realidade humana, estamos falando de algo que está nos outros e em nós, mas que não se confunde com o que Zubiri chama estritamente de realidade. Para o nosso filósofo, realidade é o que apreendemos da coisa real. Nesse sentido é também o que apreendemos de nós mesmos. Por isso, para Millás, a realidade em Zubiri constitui um enigma: “Zubiri analisou o fato do 'mais', o fato de que o momento de realidade na coisa excede a realidade da coisa e é ao mesmo tempo momento constitutivo do poder do real". ${ }^{16}$ Em outras palavras, Millás está afirmando que realidade é mais do que a coisa real, mas é um mais determinado pela coisa mesma, porque o real tem poder de nos subjugar e nos imergir nele mesmo. Realidade é o que apreendemos da coisa real em três modos: o modo primário e radical, o modo em logos e o modo em razão. O modo primário e radical é aquele em que apreendemos a realidade da coisa direta, imediata e unitariamente. Com isto, Zubiri afirma, contra todos os racionalismos e idealismos, que temos acesso direto às coisas enquanto coisas. Isso rebate, segundo Sancho, o pensamento de Nietsche que dizia que "não temos mais do que 'metáforas das coisas', por conseguinte, perspectivas que lhes são estranhas e inadequadas". ${ }^{17}$ Pintor-Ramos faz uma crítica à própria Filosofia por sua perda de contato direto com as coisas, "ao introduzir mediações entre ela e a realidade". ${ }^{18}$ Como diz Gracia, "não há razão pura, senão inteligência senciente, e o único mundo é o real, o sensível ou o senciente. Não é possível ir mais além deste limite, que atua ao modo de horizonte que não é possível ultrapassar". ${ }^{19}$ Gracia se refere â obra de Kant. Segundo Ferraz "a obra kantiana mais famosa é a 'Crítica da razão pura' (1781). Ali se pretende fundar a possibilidade do conhecimento, tanto em geral como o científico em particular, e fixar seu valor e seus limites". ${ }^{20}$

Já questionava Zubiri, em 1923: “Como é possível que afastando-nos da realidade cheguemos a ter um conhecimento mais perfeito dela" ${ }^{21}$ Então é necessário frisar desde já que isso constituiu a crise da metafísica a que

\footnotetext{
${ }^{15}$ ZUBIRI, X., Sobre la realidad, p. 32.

${ }^{16}$ MILLÁS, J., La realidad de Dios, p. 107.

${ }^{17}$ SANCHO, J. C., El pode de la mentira, p. 57.

${ }^{18}$ PINTOR-RAMOS, A., Genesis y formación de la filosofia de Zubiri, p. 33.

${ }^{19}$ GRACIA, D., El poder de lo real, p. 663-664.

${ }^{20}$ FERRAZ, A. F., Ser humano do século XXI atreve-se a pensar, p. 121.

${ }^{21}$ ZUBIRI, X., Ensayo de una teoria fenomenológica del juicio, p. 19.
} 
chegamos no contexto moderno. E a questão atinge a Teologia que "não pode nem deve prescindir da metafísica". ${ }^{22}$ Mas não pode trata-se da metafísica que está em crise desde a segunda metade do século XIX, como afirmam Tejada e Cherubin. ${ }^{23}$ Heidegger tenta encontrar solução quando, segundo Gracia, "pensou sempre que o ser não é ente, e que tratar de conceituá-lo com as categorias próprias dos entes é confundir o 'ontológico' com o meramente 'ôntico', o grande mal da metafísica ao largo dos séculos". ${ }^{24}$

Então aprendemos sim a coisa enquanto coisa. Apreendemo-la diretamente porque não há nenhuma distância intelectiva entre apreensor e a coisa real; apreendemo-la imediatamente porque não há nenhuma mediação; apreendemo-la unitariamente porque a coisa real se dá como um todo, mas de forma compacta. É a "compacção" da apreensão primordial de realidade. Tudo está aí, mas de forma compacta. E a própria realidade assim apreendida nos impele ao logos e à razão em desdobramento ulterior.

É importante frisar que a realidade é "física", porque não é uma ideia ou um mero conceito descolado da realidade. É assim porque o conceito físico não surge de uma especulação lógica, mas já está de forma compacta na apreensão primordial que se faz por impressão de realidade. Esta tem tamanha desenvoltura que até se confunde com a própria realidade:

A realidade não são simplesmente conceitos, não tem lógica, não são juízos a priori ou a posteriori, não é representação, nem consciência e nem compreensão; é a experiencia radical definitivamente, não subjetivista, é impressão de realidade. ${ }^{25}$

Não é diferente do que Gonzáles afirma: "Mais radical que o logos dos entes, mais radical do que toda a compreensão do ser, está a 'impressão de realidade'. Esta é o ponto de partida radical das reflexões de Zubiri". ${ }^{26}$

Então o conceito está na impressão de realidade, "é o momento do sentir". ${ }^{27}$ Portanto, o conceito é físico, porque é real. E isso distingue a filosofia de Zubiri de toda a filosofia que o antecedeu. O logos também é apreendido

${ }^{22}$ GONZÁLEZ, A., La novedad teológica de la filosofia de Zubiri, p. 20.

${ }^{23}$ TEJADA, J. F.; CHERUBIN, F., “O amor à sabedoria” em Xavier Zubiri, p. 43.

${ }^{24}$ GUILLÉN, D. G., El problema del fundamento, p. 43.

${ }^{25}$ TEJADA, J. F.; CHERUBIN, F. O que é a inteligência? Filosofia da realidade em Xavier Zubiri, p. 43.

${ }^{26}$ GONZÁLEZ, A., La novedad teológica de la filosofia de Zubiri, p. 19.

${ }^{27}$ ZUBIRI, X., Inteligência e realidade, p. 50. 
primordialmente, mas de forma compacta. $O$ fato de desconhecer a gênese real do logos gerou o que Zubiri chama de "logificação da inteligência". Foi isto que estabeleceu um logos independente da realidade, resultando na separação teoria e práxis, Teologia e realidade, liturgia e vida.

A apreensão primordial de realidade, por ser direta, imediata e unitária não constitui nenhum movimento intelectivo; é meramente um dado intelectivo que se faz sencientemente, ou seja, se dá pelos sentidos em impressão de realidade. A apreensão intelectiva direta, imediata e unitária não se reduz a si mesma, mas se desdobra em outros modos, que não podem ser desligados do primordialmente apreendido. E não se trata de movimento espacial, mas de movimento intelectivo, distanciamento intelectual. É a conexão do estar junto, estar em direção, estar distante ${ }^{28}$ intelectualmente.

\subsection{Campo de realidade}

Aqui nos encontramos com algo de extrema importância para o pensamento de Zubiri, que é tema do segundo volume da Inteligência senciente: inteligência e logos. Aliás, era este volume que Zubiri pensava começar escrevendo sobre a inteligência senciente, mas quando percebeu que necessitava de uma base conceitual para que a apresentação da inteligência em logos pudesse fluir mais facilmente, escreveu inteligência e realidade. Lembramos que a filosofia de Zubiri, pelo seu caráter inovador, pode parecer uma floresta terminológica, uma vez que o filósofo espanhol se sente livre para reinterpretar conceitos antigos e criar neologismos em abundância. Mas aí está a grandeza da inteligência senciente e do pensamento humano, cuja base está no acesso que o homem tem à realidade pela atualização em impressão de realidade, isto é, pelo fato de sentir. Não se trata daquele sentir como faculdade distinta da faculdade de inteligir, pois "no sentir humano, sentir já um modo de inteligir e inteligir já é um modo de sentir a realidade". ${ }^{29}$ Lembrando que ao falar de realidade enquanto o apreendido da coisa real, está suposto que não se intelige a realidade senão sentindo. Então a revolução que Zubiri faz na teoria do conhecimento é determinada pela práxis da inteligência senciente.

Sentir e inteligir não são, portanto, dois atos, nem sucessivos, nem simultâneos, nem parciais, mas dois momentos estruturais de um só ato.

\footnotetext{
${ }^{28}$ ZUBIRI, X., Acerca del mundo, p. 52.

${ }^{29}$ ZUBIRI, X., Inteligência e logos, p. 5.
} 
Esta estrutura única é, portanto, inteligência senciente: uma unidade estrutural formal, cujo ato único é a mera atualização impressiva do real. ${ }^{30}$

Já vimos que a apreensão primária e radical da realidade de cada coisa real é aquela que fazemos direta, imediata e unitariamente, ou seja, a apreensão primordial. E o fazemos em impressão de realidade. A palavra impressão engloba a totalidade dos sentidos e da ação desenvolvida por eles na apreensão do de seu, isto é, do que é próprio a cada realidade apreendida. E justamente "o campo é antes de tudo e sobretudo um momento da formalidade de realidade de cada coisa real" ${ }^{31}$ Portanto, o campo faz parte da "forma" em que apreendemos a realidade da coisa real. Cada coisa real apreendida abre o campo de realidade. Mas por sua vez, o campo inclui esta coisa aprendida (realidade) e a abarca, sendo ali onde o logos desempenha sua mais grave função. Poderíamos pensar que o campo fosse o momento do logos, mas não é verdade. O campo é sim onde o logos desenvolve sua mais grave função. No entanto, "o campo não só não é algo privativo do logos, mas tão pouco é primariamente um momento do logos. É um momento do logos, mas consecutivo, isto é, derivado da apreensão imediata".

Porém, há sempre uma dificuldade terminológica para se descrever o campo. E um dos limites é o caráter redutivo dos termos tomados da apreensão visual, ${ }^{32}$ os quais constituem uma tendência natural de qualquer descrição. Nesse sentido, o campo se reduzira a uma espécie de gravura. Mas não podemos nos esquecer que na unidade do campo há música, há vestígios, há descolamentos, já que o campo de realidade é algo em contínua variação. Portanto, a linguagem visual é pobre e insuficiente para descrever o campo, pois ele tem de ser descrito como âmbito de realidade.

Então, considerando o que já foi dito, o campo de realidade não retrata a natureza morta de uma gravura, por mais bela que fosse, mas a natureza viva do real aprendido na formalidade de realidade, naquilo que fica como realidade no apreensor. Por isso, o campo tem uma estrutura geral muito importante e pontual: é a posicionalidade com que as realidades incluídas e abarcadas se mantêm em função umas das outras. Aqui vale a pena insistir nas palavras de Zubiri:

Antes de tudo há no campo uma ou várias coisas que são as diretamente apreendidas: constituem o primeiro plano do campo. E, quando esse

\footnotetext{
${ }^{30}$ ZUBIRI, X., Inteligência e logos, p. 5.

${ }^{31}$ ZUBIRI, X., Inteligência e logos, p. 11.

${ }^{32}$ ZUBIRI, X., Inteligência e logos, p. 11.
} 
primeiro plano se reduz a uma só coisa, esta coisa adquire então o caráter de centro do campo. ${ }^{33}$

Não há como não dizer depois do texto acima que a nossa pesquisa chegou numa fase luminosa, já que o unum necessarium cristológico está não só vislumbrado, mas indicado contundentemente nesta afirmação de Zubiri, em que aparecem dois termos posicionais: primeiro plano e centro. $\mathrm{O}$ próprio autor escreve com destaque as duas palavras no texto. No primeiro plano pode haver mais de uma realidade; no centro apenas uma, que parece corresponder ao unum necessarium mencionado. Mas não vamos esgotar a discussão agora, porque é importante saber como as outras coisas se posicionam então.

Com respeito a esse primeiro plano, as outras coisas constituem o domínio do demais. E essas demais coisas têm uma precisa articulação com o primeiro plano. Em primeiro lugar, algumas destas constituem o fundo contra qual se apreendem as coisas do primeiro plano. Essa dimensão constitui o destacamento: as coisas do primeiro plano se destacam contra o fundo das outras. ${ }^{34}$

Se no primeiro plano há só uma coisa que, por isso mesmo se torna central, o unum necessarium, há que se pensar nesse fundo cuja função é destacar o que constitui o centro do campo de realidade. Vamos desenvolver esta questão mais à frente. Agora nos perguntamos: o que há mais além do centro e do fundo?

Mas em segundo lugar, há outras coisas que não são sequer o fundo, mas simplesmente algo que fica na periferia do campo. Graças a isto as outras coisas do campo adquirem uma dimensão de proximidade ou afastamento. A periferia não é a rigor uma linha, mas uma variável. À medida em que se estendem as coisas da periferia, vão ficando distantes até se perderem progressivamente. Por isso, a periferia é a área do indefinido, seja porque não está definida em si mesma, seja porque ainda que esteja, pode passar despercebida por mim. ${ }^{35}$

É a tríplice dimensão do campo: primeiro plano, fundo e periferia. E aqui temos toda a base para desenvolver uma teologia do campo de realidade

${ }^{33}$ ZUBIRI. X., Inteligência e logos, p. 12.

${ }^{34}$ ZUBIRI, X., Inteligência e logos, p. 12.

${ }^{35}$ ZUBIRI, X., Inteligência e logos, p. 12. 
zubiriano. Mas antes queremos insistir em clarear ainda algumas terminologias zubirianas necessárias para este estudo, a fim de concluirmos com segurança o que nos propusemos nesta pesquisa.

\subsection{O indefinido e sua diferença do "não definido"}

Uma das coisas importantes é definir o indefinido para Zubiri. O autor insiste rigorosamente que indefinido não é o mesmo que não definido. "A indefinição já é um modo de definição". ${ }^{36}$ A questão se levanta, quando Zubiri diz que na periferia resta o indefinido. E afirma que para além do horizonte, que funciona como linha demarcatória que estabelece o que fica "da porta para dentro" e o que fica "da porta para fora" no campo de realidade. O que fica para além do horizonte é o não definido.

\subsection{O panorama campal}

Mais um termo importante para descrever o que fica da porta para dentro ou o aquém da linha do horizonte do campo de realidade, usando uma linguagem visual, é o panorama. "Sinopse e sintaxe são os aspectos da unidade panorâmica da apreensão". ${ }^{37}$ Esta unidade faz com que o panorama seja sempre variável. A sinopse apreensiva das coisas reais tem sempre uma disposição variável destas mesmas coisas (sintaxe), pois a estrutura do campo não é fixa, mas variável. E a dimensão segundo a qual o campo é variável tanto por ampliação como por retração é o que Zubiri chama de amplitude". ${ }^{38}$ A primeira consequência desta amplitude é o deslocamento do horizonte e a reorganização interna do campo. Portanto, está posta aí uma mobilidade que faz da realidade campal um movimento real.

Outro dado importante é o que chamamos campo perceptivo, que corresponde ao conteúdo das coisas reais abarcadas nele. Aí a entrada de uma nova coisa real representa uma adição. Então o campo cresce aditivamente sem deslocar o horizonte. Porém, quando falamos de campo de realidade, nos referimos a uma só realidade numericamente imutável. Toda entrada de uma nova realidade que não estava aí antes faz o campo crescer dilatativamente e não numericamente. Neste caso, o que vai acontecer é o deslocamento do

\footnotetext{
${ }^{36}$ ZUBIRI, X., Inteligência e logos, p. 13.

${ }^{37}$ ZUBIRI, X., Inteligência e logos, p. 13.

${ }^{38}$ ZUBIRI, X., Inteligência e logos, p. 13.
} 
horizonte e, em consequência, uma nova reorganização interna do campo. Para nós seria como a função do fermento no pão. E esta questão é fundamental para a análise teológica que estamos fazendo neste artigo.

\section{5. Âmbito transcendental}

Âmbito transcendental é uma expressão importante no contexto da atualização campal. Zubiri salienta o olhar por meio de duas lentes: uma que olha o campo através das coisas e outra que olha as coisas através do campo. Ambas são legítimas, mas não têm o mesmo efeito. A lente que olha o campo através das coisas vai perceber que no campo as coisas são mais do que elas mesmas enquanto conteúdo. É a transcendência que revela a tendência do hacia (para) que as coisas reais mesmas trazem em si. É uma abertura que ninguém pode deter. Cada coisa tende (hacia) para mais realidade e, por isso, estão abertas umas às outras. Aqui o conceito de transcendência zubiriana é totalmente novo. Não se trata de transcendência para além da realidade, mas de transcendência $n a$ realidade. O próprio Zubiri compara a transcendência com a gota de óleo: "É algo assim como uma gota de óleo que se estende desde si mesma, desde o óleo mesmo". ${ }^{39}$

Já a lente que vê as coisas reais através do campo enxerga a "formalidade de realidade como âmbito de realidade". ${ }^{40}$ Tanto a transcendência como o âmbito não são como que invólucros ou uma atmosfera envolvente. Transcendência e âmbito estão nas coisas e só nas coisas. Transcendência e âmbito são determinados pelas coisas reais. Como já dissemos, o campo que as coisas mesmas determinam as inclui e as abarca. $\mathrm{O}$ âmbito é o que determina o ambiente nas coisas. Então "âmbito e transcendentalidade não são senão dois aspectos de um só caráter: o caráter campal do real sentido. Esse caráter é o que unitariamente chamamos de âmbito transcendental". ${ }^{41}$ Portanto, o que já está no título desta pesquisa, âmbito transcendental, são os dois aspectos de um só caráter do campo de realidade. Então, já fica clareado porque falamos da posição que em que Cristo deve estar no âmbito transcendental do campo de realidade da fé. Por fim, é necessário abordar na estrutura do campo de realidade o que é atualização de umas coisas entre outras e umas coisas em função de outras.

${ }^{39}$ ZUBIRI, X., Inteligência e realidade, p. 82.

${ }^{40}$ ZUBIRI, X., Inteligência e logos, p. 18.

${ }^{41}$ ZUBIRI, X., Inteligência e logos, p. 19. 
O campo de realidade é aquele momento em que as coisas não são vistas individualmente, mas campalmente. E necessariamente aí as coisas estão umas entre outras e, ao mesmo tempo, em função de outras, que já é um modo também de estar entre. "O entre não é mero conglomerado. Tampouco é a mera relação de umas coisas com outras, mas uma estrutura muito precisa: a estrutura da atualização de umas coisas entre outras". ${ }^{42}$

As coisas estão entre as outras em razão da sua atualidade. Isto quer dizer que as coisas estão entre outras quando estão presentes na intelecção. "É por isso que as coisas não estão somente umas entre outras, por assim dizer, materialmente, em atuidade, mas têm umas com respeito às outras uma posição, estão umas entre outras em razão da sua atualidade". ${ }^{43}$

Em Zubiri, atuidade e atualidade são coisas independentes, mas diferentes. Atuidade é o caráter da coisa real que existe enquanto tal, mas não atualizada na intelecção. É como um stand by. Se existe é porque tem caráter real, mas falando em linguagem comum, não é percebida na inteligência. Um dos exemplos que Zubiri evoca são os vírus. Devem existir há milhões de anos, mas não eram atualizados na inteligência senciente. Então essas coisas não têm realidade, mas somente reidade, porque realidade é justamente a atualização da coisa real em inteligência senciente. Em contraposição, a realidade só pode ser porque está fundada na reidade.

E aqui convém insistir no campo de realidade enquanto atualização. Não é um campo de reidade, mas de realidade, isto é, de realidade atualizada em inteligência senciente. Ao falar da posição em que Cristo está no âmbito transcendental do campo da fé, estamos falando de atualização e não de atuidade. Uma coisa já atualizada como sabemos que foi a realidade cristã depois da ressureição de Cristo, se não continuar sendo atualizada com todo o sistema sacramental e místico e pastoral com que deve contar, vai ficando em stand bye e, aos poucos, desaparece do horizonte do campo de realidade da fé. Uma pergunta de extrema pertinência é se não estamos vivendo uma situação similar na cultura pós-moderna e digital? Todas as apreensões da fé enquanto realidade foram vividas pelos Apóstolos que conviveram diretamente com Cristo histórico e vividas por aqueles apóstolos que não tiveram igual

\footnotetext{
${ }^{42}$ ZUBIRI, X., Inteligência e logos, p. 21.

${ }^{43}$ ZUBIRI, X., Inteligência e logos, p. 21.
} 
oportunidade, mas, no entanto, conseguiram com a mesma profundidade ou até maior apreender a realidade cristã. Entre os apóstolos que estão neste caso, São Paulo é o exemplo maior. E esta realidade continuou sendo atualizada pelos milênios seguintes, mas pode ter sofrido um breik que convém analisar. Esta é uma questão que este artigo suscita, mas não pretende resolver, porque requer muito mais discussão. Porém, vamos ainda falar da atualização de umas coisas em função de outras.

Toda e qualquer coisa real é campalmente atualizada não só 'entre' outras coisas, mas também em função dessas outras. Posição, por exemplo, é próprio de uma coisa "entre" outras, mas é um "entre "em que cada coisa tem a posição que tem em função de outras e varia em função de outras, e, portanto, desaparece sempre e somente em função dessas outras. ${ }^{44}$

Vimos que cada coisa real determina o campo, mas o modo como cada coisa real é incluída no campo "tem um caráter intrínseco e formal de funcionalidade". ${ }^{45}$ Como estávamos vendo, a dependência que constitui o caráter posicional das coisas no campo é a coexistência. Então é desse tipo de funcionalidade que estamos tratando neste artigo, ou seja, a posição em que Cristo deve estar no âmbito transcendental do campo da fé. Aqui nós já temos os elementos metafísicos e noológicos zubirianos suficientes para traçar a posição em que Cristo deve estar no âmbito transcendental do campo da fé.

\section{Encontro entre Filosofia e Teologia na realidade campal: a centralidade}

Já vimos também que a centralidade posicional no campo corresponde ao fato de uma só coisa estar no primeiro plano, conforme Zubiri. Não é possível fazer uma leitura do unum necessarium cristológico que se enquadre fora da centralidade campal zubiriana. Dentre as parábolas do Reino dos Céus, as parábolas do tesouro e da pérola ilustram o argumento do unum necessarium:

O Reino dos Céus é semelhante a um tesouro escondido num campo: um homem o acha e torna a esconder e, na sua alegria, vai, vende tudo o que tem e compra aquele campo. O Reino dos Céus é ainda semelhante ao

\footnotetext{
${ }^{44}$ ZUBIRI, X., Inteligência e logos, p. 22.

${ }^{45}$ ZUBIRI, X., Inteligência e logos, p. 22.
} 
negociante que anda em busca de pérolas finas. Ao encontrar uma pérola de grande valor, vai, vende tudo o que possui e a compra (Mt 13,44-46).

Estas duas parábolas têm o timbre de centralidade, na medida em que se vende tudo o que se tem para comprar o tesouro ou a pérola de grande valor. A razão de se vender tudo o que tem é a justificação funcional da possessão do que é central. O resto é o demais zubiriano, que está em função do que é central, pois a realidade central é única. $\mathrm{O}$ caçador de tesouros ou de pérolas valiosas passa, quando consegue o que busca, a deter-se e determinar-se, centralizando, ele também, nessa escolha. $O$ resto é o demais. Umas coisas constituem o fundo e outras a periferia do campo. As do fundo estão em estreita proximidade da coisa central, porque sua função é destacar a coisa central.

A questão que está em nossa pesquisa é o campo de realidade da fé. Não resta dúvida de que a fé é uma realidade apreendida da coisa real por excelência, que é Cristo, enquanto realidade histórica e decisiva para a vida de milhões de pessoas. Temos o Novo Testamento, amparado pelo Antigo, e ambos constituem as Escrituras. Temos também o ensino magisterial ao longo de mais de dois milênios e a história tecida na Tradição. História, para Zubiri, como diz Cavero, é o
processo em que uns homens vão transmitindo aos outros aquilo que são e sabem, quer dizer, suas mais profundas possiblidades de vida pessoal, em um caminho que os vincula uns com os outros e abre a todos ao futuro de sua própria identidade. ${ }^{46}$

Assim podemos entender como o Apóstolo Paulo, aprendeu a realidade da fé sem ter convivido historicamente com Jesus. E foi ele mesmo um dos articuladores do Novo Testamento com suas cartas, que deixaram o lastro profundo de um testemunho de fé e ousadia. A busca de Paulo pode ser comparada ao do caçador de tesouros e de pérolas valiosas. Uma vez encontrado o objeto de sua busca, ocorre o que Zubiri chama de reorganização interna do campo e dilatação do horizonte. E esta dilatação constituiu a Igreja Católica. Esta reorganização é algo profundo que estabelece uma funcionalidade nova entre as coisas que estão no campo. Uma coisa que vai para o plano central estabelece outra posição para as demais coisas. Aquelas que destacarem o primeiro plano são bem-vindas.

$\overline{{ }^{46} \text { CAVERO, J. M. C., Salvar la historia, p. } 16 .}$ 
As demais vão para a periferia ou até mesmo para fora do horizonte. É neste aspecto que o Apóstolo diz:

Mais ainda, tudo considero perda, pela excelência do conhecimento de Cristo Jesus, meu Senhor. Por ele, perdi tudo e tudo tenho como esterco, para ganhar a Cristo e ser achado nele, não tendo como minha justiça aquela que vem da Lei, mas aquela pela fé em Cristo, aquela que vem de Deus e se apoia na fé (Fl 3,8-9).

Então podemos afirmar tranquilamente que Cristo foi o unum necessarium para Paulo, com toda a extensão do significado. A conversão do Apóstolo às portas de Damasco ilustra bem o teor de mudança de sua vida; foi mudança radical e amadurecida em todos os anos que lhe restaram. Por isso, Paulo é um exemplo de conversão e de atuação missionária. Com isto provamos o que já dissemos no início: a posição em que Cristo deve estar no âmbito transcendental do campo da fé é central.

Há aqui uma delicadeza de expressão. Não se disse a posição de Cristo, pois pareceria uma posição dada pura e simplesmente. Dada pura e simplesmente é a apreensão primordial de realidade cristã. Paulo expressa isso quando diz; "ser achado nele (Cristo)" (Fl 3,9). Ao contrário, afirmar que a posição em que Cristo deve estar no centro supõe uma intelecção campal. Portanto, supõe uma escolha humana, porque intelecção é um ato humano. Toda intelecção campal não é feita direta, imediata e unitariamente como a intelecção primária. Agora a intelecção é feita de forma distanciada na busca incansável do que a coisa é em realidade. São as simples apreensões que determinam a dimensão fatigosa do conhecimento em nossa vida. É o que chamamos de labor das simples apreensões. Esse é o labor de uma vida de fé e dedicação ao Mistério Pascal. A vida cristã é uma vida nova e cheia de perspectivas, mas não é uma vida fácil; é laboriosamente comprometida com a verdade real, que é a verdade da apreensão primordial, a qual sequer pode conter erro, porque a verdade real é o que é. Não admite julgamento. Isso tem de ser feito no âmbito do logos em sua atuação campal.

"Para uma inteligência que inteligisse o real em e por si mesmo exaustivamente, não haveria afirmações nem mundo intelectivo". ${ }^{47}$ Seria uma inteligência divina. Mas, "o homem existe já como pessoa, no sentido de ser um ente cuja entidade consiste em ter que realizar-se como pessoa, ter que

${ }^{47}$ ZUBIRI, X., Inteligência e logos, p. 289. 
elaborar sua personalidade na vida". ${ }^{48}$ Aí está a grandeza e a pequenez da inteligência humana: intelige primordialmente tudo, mas de forma compacta. Por isso, é impelido "exigencialmente" ao penoso e árduo labor de inteligir em desdobramentos ulteriores sem nunca dar por encerrada esta tarefa, pois a abertura transcendental da realidade não se dará por encerrada enquanto o último homem deixar de existir no mundo. Mesmo a atitude de Cristo como Messias não teve a intenção de fazer dos homens criaturas espetaculares, mas ajudá-los a fazer da vida um labor em busca de um conhecimento fatigoso. Neste sentido, como o povo de Israel estava mais ou menos aclimatado à ideia de milagre, Cristo não fez milagres como prova de sua divindade, mas pura e simplesmente como sinais da sua missão. ${ }^{49}$ Por isso, "nunca quis que o milagre fosse uma esplêndida teofania que deixasse os homens estupefatos" 50 e propensos a abandonar as simples apreensões como tarefa árdua de cada dia.

Com essas considerações, estamos afirmando que a posição em que Cristo deve estar no âmbito transcendental do campo da fé é o central Sim, Cristo deve estar no centro, mas essa função depende também do homem que adere a Cristo como discípulo. O empenho fatigoso de atualização desta realidade é tarefa da pessoa convertida que esteja disposta a permitir e promover uma reorganização campal de sua vida.

\section{Conclusão}

O objeto formal deste artigo foi, de certa forma, ousado. Pesquisar a posição em que Cristo deve estar no âmbito transcendental do campo da fé não é ousado do ponto de vista da própria fé, pois a centralidade do Senhor é uma norma que ele deu à Marta de Belém. Mas é ousado no momento em que o objeto material é o campo de realidade zubiriano. Zubiri é filósofo e não escreveu especificamente para teólogos. Porém os teólogos devem ousar, em conhecimento interdisciplinar, a fazer tal aplicação. Pareceu-nos que nossa ousadia chegou a um fim feliz. O leitor que o julgue.

Encontramos no árduo estudo de um filósofo complexo como Zubiri a base para que nossa interface obtivesse êxito. Primeiramente o unum necessarium se enquadrou perfeitamente numa das funções posicionais da estrutura do campo de realidade em Zubiri: o centro. Comparamos com as

${ }^{48}$ ZUBIRI, X., Naturaleza, história, Dios, p. 427.

${ }^{49}$ ZUBIRI, X., Sobre la religión, p. 183.

${ }^{50}$ ZUBIRI, X., Sobre la religión, p. 183. 
parábolas do Reino em Mateus, sobretudo a do tesouro escondido no campo e a pérola de grande valor. Depois adentramos alguns elementos da mística paulina, e foi, a nosso ver, perfeito.

O que fica patente é a crítica do atual catolicismo que deixou de atualizar o campo de realidade da fé e se encontra em grande dificuldade. Mas a análise que fizemos deve nos estimular a buscar a solução na retomada da atualização do campo de realidade da fé. Pela falta de atualização, por meio do sistema sacramental, místico e pastoral, parece que as coisas foram ficando stand by e podem ter saído do horizonte do campo da fé ou permanecido indefinidas na periferia. É uma negação absoluta do unum necessarium e um descuido perigoso. A nós causa júbilo perceber que a interface com um filósofo do quilate zubiriano ajuda-nos a enfrentar a crítica e estimula a refazer o caminho da atualização do campo da fé. Parece-nos que não há outra saída. É uma saída viável e promissora que podemos chamar de "evangelização missionária".

\section{Referências bibliográficas}

BÍBLIA de Jerusalém. Nova ed. rev. e ampl. São Paulo: Paulus, 2012.

CAVERO, J. M. C. Salvar la historia: historia, religión y religiones en Xavier Zubiri. Zamora: Monte Cassino, 2004.

FERRAZ, A. F. Ser humano do século XXI atreve-se a pensar. Granada: Comares, 2013.

GONZÁLEZ, A. La novedad teológica de la filosofia de Zubiri. Madri: Fundação Xavier Zubiri, 1993.

GRACIA, D. El poder de lo real: leyendo a Zubiri. Madrid: Funcación Xavier Zubiri / Triacastel, 2017.

GUILLÉN, D. G. El problema del fundamento. In: NICOLÁS, J. A.; ESPINOZA, R. Zubiri ante Heidegger. Barcelona: Herder, 2008. p. 33-79.

MANERO, M. M. Era Independiente de Ortega. In: COROMINAS, J.; VINCENS, J. A. Conversaciones sobre Xavier Zubiri. Madri: PPC, 2008. p. 33-47. MILLÁS, J. M. La realidad de Dios: Su justificación y sentido en Xavier Zubiri y Javier Monserrat. Roma / Madri: E.P.U.G. / Comillás, 2004.

PINTOR-RAMOS, A. Genesis y formación de la filosofia de Zubiri. Salamanca: Universidad Pontificia, 1996.

PINTOR-RAMOS, A. Nudos de la filosofia de Zubiri. Salamanca: Universidad Pontificia, 2006. 
SANCHO, J. C. El poder de la mentira: Nietzsche y la política de la transvalorización. Madri: Editorial Tecnos, 2007.

SANCHO, J. C. Zubiri y Heidegger desde Ortega y Gasset. In: NICOLÁS, J. A.; SPINOZA, R. Zubiri ante Heidegger. Barcelona: Herder, 2008. p. 81-106. SOLARI, E. La raíz de lo sagrado: contribuiciones de Zubiri a la filosofia de la religión. Santigo: RIL, 2010

TEJADA, J. F.; CHERUBIN, F. "O amor à sabedoria" em Xavier Zubiri: situação histórica e filosófica do problema e elaboração do philein zubiriano. In: TEJADA, J. F.; CHERUBIN, F. O que é a inteligência? Filosofia da realidade em Xavier Zubiri. Rio de Janeiro: Lumen Iuris, 2016. p. 43-69.

TIRADO SAN JUAN, V. M. Husserl et Zubiri. Six études pour une controverse. Paris: L'Harmattan, 2005.

ZUBIRI, X. Acerca del mundo. Madrid: Alianza Editorial, 2010.

ZUBIRI, X. Naturaleza, história, Dios. Madrid: Alianza Editorial, 2015.

ZUBIRI, X. Estrutura dinámica de la realidad. Madri: Alianza Editorial, 2016.

ZUBIRI, X. Inteligência e logos. São Paulo: É realizações, 2011.

ZUBIRI, X. Inteligência e razão. São Paulo: É realizações, 2011.

ZUBIRI, X. Inteligência e realidade. São Paulo: É realizações, 2011.

ZUBIRI, X. Sobre la religión. Madrid: Alianza Editorial, 2017.

ZUBIRI, X. Sobre la realidad (1966). Madri: Alianza Editorial, 2018.

ZUBIRI. X. Ensayo de una teoria fenomenológica del juicio. Madri: Revista de Archivos, biblioteca y museos, 1923.

Valeriano dos Santos Costa Doutor em Sagrada Liturgia pelo Pontifício Instituto Litúrgico Sant'Anselmo Docente do Programa de Pós-Graduação em Teologia da Pontifícia Universidade Católica de São Paulo

São Paulo / SP - Brasil E-mail: pvaleriano@uol.com.br

Recebido em: 27/04/2020

Aprovado em: 13/05/2021 